\title{
Clinical Reasoning: An 81-Year-Old Woman Who Insisted the Hospital Was Her Home
}

Tara C. Carlisle, MD, PhD, Michael P.H. Stanley, MD, Aneesh B. Singhal, MD, and David N. Caplan, MD

Neurology ${ }^{\circledR}$ 2021;97:e1632-e1636. doi:10.1212/WNL.0000000000012392
Correspondence

Dr. Carlisle

tara.carlisle@

cuanschutz.edu

\section{Section 1}

An 81-year-old right-handed White non-Hispanic previously healthy woman with glaucoma presented with acute weakness and slurred speech nearly 10 hours after last seen well. She was found to have new onset atrial fibrillation. Her NIH stroke scale (NIHSS) was 18 with points given for failure to answer questions, left lower facial paralysis, right gaze preference with ability to cross midline, left field cut, left hemiplegia, severe dysarthria, mild aphasia, and severe left sensory neglect.

\section{Question for Consideration:}

1. What is the localization and differential diagnosis?

GO TO SECTION 2

From the Department of Neurology (T.C.C.), Behavioral Neurology and Neuropsychiatry Section, University of Colorado School of Medicine, Aurora; Department of Neurology (M.P.H.S.), Brigham and Women's Hospital; Department of Neurology (M.P.H.S., A.B.S., D.N.C.), Massachusetts General Hospital; and Harvard Medical School (M.P.H.S., A.B.S., D.N.C.), Boston, MA.

Go to Neurology.org/N for full disclosures. Funding information and disclosures deemed relevant by the authors, if any, are provided at the end of the article.

T.C. Carlisle and M.P.H. Stanley should be listed as cofirst authors. 


\section{Section 2}

The left-sided hemiplegia, right gaze preference, and left visual and sensory neglect localize to the right hemispheric cortical and subcortical regions. Her acute presentation and new onset atrial fibrillation implicate an embolic stroke in the right middle cerebral artery (MCA); however, other nonembolic stroke etiologies and intraparenchymal hemorrhage are also considered. Todd paralysis resulting from a focal seizure is possible. Intracranial mass lesions from malignancy or infection and inflammatory/demyelinating conditions would also be a consideration; however, there was no indication of even subtle previous neurologic or systemic symptoms preceding her acute presentation.

CT head examination with CT angiography (CTA) head and neck examinations confirmed an acute thrombus in the distal right M1 and proximal M2 segments with infarction throughout the right MCA territory.

Question for Consideration:

1. What are the next steps in management and treatment?

GO TO SECTION 3 


\section{Section 3}

She was not a candidate for the IV tissue plasminogen activator given last seen well or intra-arterial therapy because of the presence of a large established infarction on initial brain imaging (Figure, A). She was administered aspirin with the plan to later convert to an oral anticoagulant.

Over 24 hours, her NIHSS improved to 10 with most gains in strength and dysarthria. She was oriented to self, month, and year, but not location despite multiple choices. Adamantly denying being in a hospital, she instead reported being in her home in another city despite evidence provided to the contrary. She pointed out the location of her kitchen, bathroom, living room, and front door with some reproducibility.

She neglected her left extrapersonal space and suffered extinction of bilateral stimulation and retrocaudal 2-point extinction. Her clock drawing possessed mirrored placement of some numbers, random absence of some numbers, irregular spacing without clear hemineglect, and misplaced hands in both origin and orientation (Figure, B). She experienced left-right confusion although without finger agnosia or acalculia. She was adamant she was left-handed while physically referring to her right hand. Her complete right-handedness was confirmed from herself and husband later.

Her language showed a mild mixed aphasia. Her speech continued to be severely dysarthric; thus, communication through writing and reading was used. Repetition was intact to simple phrases with paraphasias. On confrontational naming, she initiated spelling of high-frequency and low-frequency words. She could not name a horse by verbal description of "an animal with a long face, long legs, and hooves with metal shoes that people can ride," instead writing "krongroog" and then "kornger" (Figure, C), but could identify a horse from image. In response to a description of a giraffe, she wrote "grafraf" (Figure, D) and could choose a giraffe correctly from multiple choice images. She was asked to copy a sentence (Figure, E) and then mimicked a "bunny" hopping across her tray when asked the meaning. She was also asked to write a spontaneous sentence (Figure, F).

\section{Questions for Consideration:}

1. What is the neurologic term for misidentifying one's location? Can this be localized?

2. Is aphasia unusual given the lesion localization?

3. What type of dysgraphia does she have? Can this be localized?
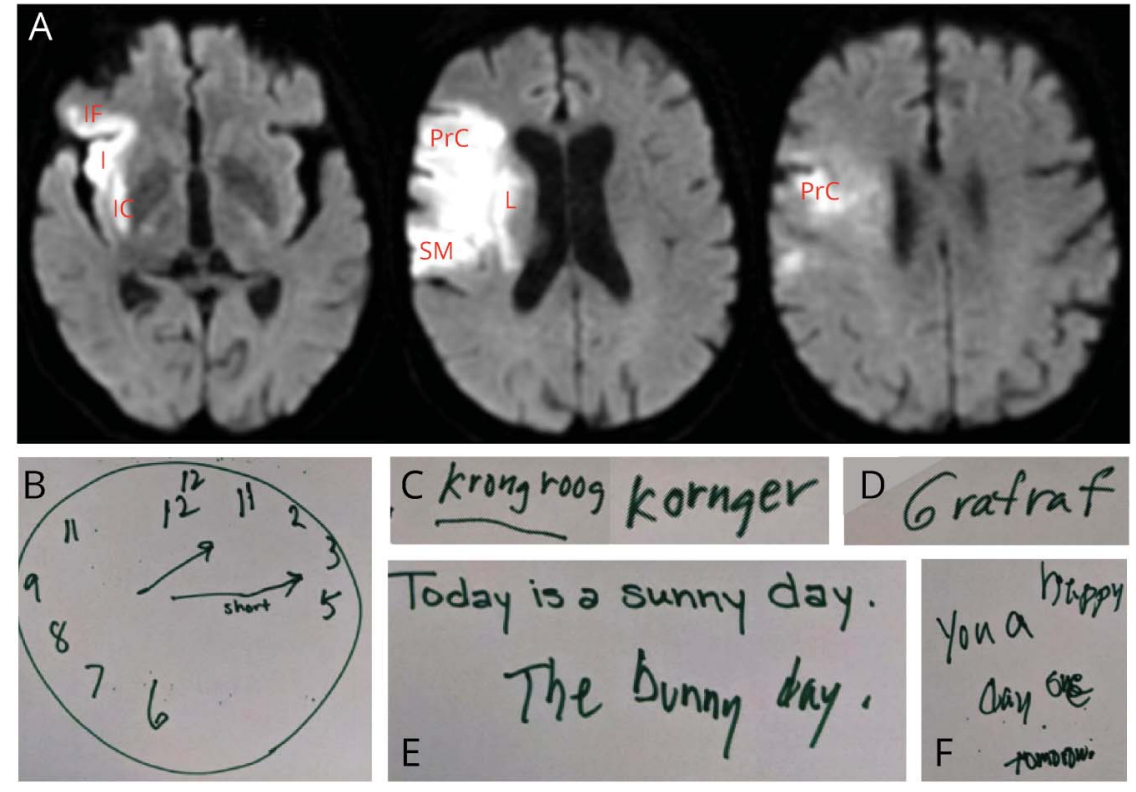

(A) DWI bright signal within the right MCA distribution including the inferior frontal gyrus (IF), insula (I), internal capsule (IC), lentiform nucleus $(\mathrm{L})$, precentral gyrus $(\operatorname{PrC})$, and supramarginal gyrus (SM) in standard radiologic orientation with patient left on the right. (B) Clock drawing. (C) Written response to the description of a horse. (D) Written response to the description of a giraffe. (E) Copy (below) of an examiner provided written sentence (above). (F) Written response when asked to write any sentence. I = insula, IC = internal capsule, IF = inferior frontal gyrus, $L=$ lentiform nucleus, $\operatorname{PrC}=$ precentral gyrus, $\mathrm{SM}=$ supramarginal gyrus. 


\section{Section 4}

Her insistence that her hospital room was instead her private home is a delusional misidentification syndrome (DMS), more specifically reduplicative paramnesia $(\mathrm{RP})$ to places (RPP). ${ }^{1}$ RPP has also been termed environmental reduplication, environmental $\mathrm{RP}$, foreign $\mathrm{RP}$, topographical delusion, misidentification, disorientation for place, spatial delirium, delusion for place, and Capgras for place. DMS as a category also includes disorders of hypofamiliarity, such as Capgras syndrome (i.e., a familiar person is replaced by an imposter), and disorders of hyperfamiliarity, such as Frégoli syndrome (i.e., a person is replaced by another in disguise), intermetamorphosis (i.e., 2 people have interchanged their physical appearance and psychological identity), and syndrome of subjective doubles (i.e., self-duplication or Doppelgänger). ${ }^{2}$

Cases of RPP frequently localize to the right hemisphere and, however, commonly have bilateral but right greater than left involvement. $^{2}$ Rarely, RPP has isolated left hemisphere involvement. ${ }^{3,4}$ Lesions are observed in the frontal lobe more commonly than temporal or parietal lobes, but also with combinations of the aforementioned lobes, occipital involvement, deeper thalamic, corona radiata, and internal capsule lesions. ${ }^{3,4}$ Often single lesions are significant in size ${ }^{3}$ while the "2-hit" theory suggests that underlying vulnerability followed by an often right hemispheric lesion causes RPP., ${ }^{4,5}$ Previous theories about the underpinnings of RPP have included purely spatial disorientation, disconnection/ disorientation of memories, disconnection of limbic (e.g., self-monitoring and error detection) from frontal regions (e.g., familiarity), and the combination of memory, visuospatial, and executive dysfunction. ${ }^{3}$ Borghesani et al. proposed that a 2 -factor theory is the most comprehensive such that a perceptual/affective deficit (the cause variable) and impaired belief evaluation (often from right lateral prefrontal involvement) are both required for the development of RPP.

Because of hemispheric specialization (HS), language is predominantly represented in the left hemisphere. ${ }^{6}$ It is important to note that our patient had no evidence of acute or previous left hemispheric injury on imaging. Handedness including familial handedness is a source of variability in language HS, although even $80 \%$ of left-handed individuals still display left hemispheric language lateralization. ${ }^{6}$ Although our patient is completely right-handed, her father was left-handed, suggesting a possible source of her right hemisphere dominance for language.

Although complicated by her language disorder, her written language is consistent with an acquired dysgraphia. Acquired dysgraphia after ischemic injury can be due to the disruption of orthographic and/or phonological processing. ${ }^{7}$ Dysfunction of orthographic long-term memory (e.g., storage and retrieval of learned word spelling) causing misspelling often of low-frequency words is associated with damage to left inferior frontal and ventral occipitotemporal regions. ${ }^{7}$ Dysfunction of orthographic working memory (e.g., maintaining letter information while actively spelling a word) causing misspelling of longer words is associated with damage to the left parietal lobe. ${ }^{7}$ Phonological processing is localized in the left perisylvian language areas including the Wernicke area, Broca area, and supramarginal gyrus. ${ }^{8}$ Disruption to phonologyorthography conversion can produce additional phonemic errors of uncommon or irregularly spelled words. ${ }^{7}$ Our patient produced other word errors (i.e., sunny = bunny), complex phonological paraphasia or phonologically implausible errors (i.e., giraffe $=$ grafraf), and semantic errors (i.e., horse $=$ possibly kangaroo). In the setting of orthographic long-term memory and phonology-orthography conversion dysfunction, there are a variety of abnormalities including semantic errors, incorrect production of other words, and production of pseudowords. ${ }^{7}$ Therefore, there seems to be both orthographic long-term memory and phonology-orthography conversion dysfunction in this case.

Five days after her acute presentation, she was discharged to a rehabilitation hospital. After nearly 2 months, she became oriented to "hospitalization" but continued to incorrectly report the city as her hometown. Her other neurologic deficits, including dysphagia, dysarthria, aphasia, left-sided weakness, and neglect, continued to improve.

\section{Discussion}

This elderly woman developed a cardioembolic right MCA ischemic stroke resulting in RPP, mixed aphasia, and acquired dysgraphia in addition to left-sided motor and sensory perception deficits.

RPP is rare making it difficult to classify and study in detail. Borghesani et al. proposed a classification system distinguishing whether duplication and/or displacement are present, including reduplication with displacement, reduplication without displacement, and displacement without reduplication. RPP itself is a problematic term because reduplication is not always present nor is memory impairment the only neuropsychological feature present in the disorder. ${ }^{3}$ $\mathrm{RPP}$ is also frequently accompanied by executive dysfunction, visuospatial deficits, and nonverbal memory impairment with additional features of confabulation, anosognosia, time disorientation, and paranoid personality traits. ${ }^{3}$

RPP is most frequently seen in the setting of an acute neurologic event or injury, although also reported in neurodegenerative disorders and neuroinflammatory conditions (i.e., Morvan syndrome) ${ }^{3,4}$ The duration of RPP is difficult to assess because patients may no longer verbalize distress despite ongoing beliefs about location unless questioned directly. ${ }^{3}$ The delusion is most often difficult to correct with behavioral modification. ${ }^{3}$ Confronting a patient with RPP about the delusion has been successful in 1 reported case 
using an unequivocal landmark for place orientation. ${ }^{9}$ Treatment has been attempted with antipsychotic medications, however with mixed results. ${ }^{3}$

Her injuries were in the right inferior frontal gyrus, insula, precentral gyrus, and supramarginal gyrus and to a lesser extent involving the internal capsule and lentiform nucleus (Figure, A). It is of interest that RPP has clearly been localized to the right hemisphere, but mixed aphasia and acquired dysgraphia are generally localized to the left hemisphere. If RPP, so often mistaken for "confusion" or simple "disorientation" in the setting of delirium, redirectable (i.e., not fixed) confabulation, or a more generalized delusional or hallucinatory state, were better recognized by performing a thorough mental status examination, it would improve our understanding of the localization and natural disease course.

\section{Study Funding}

The authors report no targeted funding.

\section{Disclosure}

The authors have no disclosures relevant to the manuscript. Go to Neurology.org/N for full disclosures.

\section{Appendix Authors}

\begin{tabular}{lll}
\hline Name & Location & Contribution \\
\hline Tara C. & Department of Neurology, & $\begin{array}{l}\text { Drafting/revision of the } \\
\text { article for content including }\end{array}$ \\
$\begin{array}{l}\text { Carlisle, } \\
\text { MD, PhD }\end{array}$ & $\begin{array}{l}\text { Behavioral Neurology and } \\
\text { Neuropsychiatry Section, } \\
\text { University of Colorado School } \\
\text { of Medicine }\end{array}$ & $\begin{array}{l}\text { medical writing for content } \\
\end{array}$ \\
\hline
\end{tabular}

Appendix (continued)

\begin{tabular}{|c|c|c|}
\hline Name & Location & Contribution \\
\hline $\begin{array}{l}\text { Michael } \\
\text { P.H. } \\
\text { Stanley, } \\
\text { MD }\end{array}$ & $\begin{array}{l}\text { Department of Neurology, } \\
\text { Brigham and Women's } \\
\text { Hospital, Department of } \\
\text { Neurology, Massachusetts } \\
\text { General Hospital, Harvard } \\
\text { Medical School, Boston, MA }\end{array}$ & $\begin{array}{l}\text { Drafting/revision of the } \\
\text { article for content including } \\
\text { medical writing for content }\end{array}$ \\
\hline $\begin{array}{l}\text { Aneesh B. } \\
\text { Singhal, } \\
\text { MD }\end{array}$ & $\begin{array}{l}\text { Department of Neurology, } \\
\text { Massachusetts General } \\
\text { Hospital, Harvard Medical } \\
\text { School, Boston, MA }\end{array}$ & $\begin{array}{l}\text { Drafting/revision of the } \\
\text { article for content including } \\
\text { medical writing for content }\end{array}$ \\
\hline $\begin{array}{l}\text { David N. } \\
\text { Caplan, } \\
\text { MD }\end{array}$ & $\begin{array}{l}\text { Department of Neurology, } \\
\text { Massachusetts General } \\
\text { Hospital, Harvard Medical } \\
\text { School, Boston, MA }\end{array}$ & $\begin{array}{l}\text { Drafting/revision of the } \\
\text { article for content including } \\
\text { medical writing for content }\end{array}$ \\
\hline
\end{tabular}

\section{References}

1. Benson DF, Gardner H, Meadows JC. Reduplicative paramnesia. Neurology. 1976; 26(2):147-151

2. Förstl H, Almeida OP, Owen AM, Burns A, Howard R. Psychiatric, neurological and medical aspects of misidentification syndromes: a review of 260 cases. Psychol Med. 1991;21(4):905-910.

3. Borghesani V, Monti A, Fortis P, Miceli G. Reduplicative paramnesia for places: a comprehensive review of the literature and a new case report. Clin Neurol Neurosurg. 2019; 181:7-20.

4. Devinsky O. Delusional misidentifications and duplications: right brain lesions, left brain delusions. Neurology. 2009;72(1):80-87.

5. Moser DJ, Cohen RA, Malloy PF, Stone WM, Rogg JM. Reduplicative paramnesia: longitudinal neurobehavioral and neuroimaging analysis. J Geriatr Psychiatry Neurol. 1998;11(4):174-180.

6. Hervé PY, Zago L, Petit L, Mazoyer B, Tzourio-Mazoyer N. Revisiting human hemispheric specialization with neuroimaging. Trends Cogn Sci. 2013;17(2):69-80.

7. Rapp B, Purcell J, Hillis AE, Capasso R, Miceli G. Neural bases of orthographic longterm memory and working memory in dysgraphia. Brain. 2016;139(pt 2):588-604.

8. Beeson PM. Remediation of written language. Top Stroke Rehabil. 2004;11(1):37-48.

9. Pignat JM, Ptak R, Leemann B, Guggisberg AG, Zahler B, Schnider A. Modulation of environmental reduplicative paramnesia by perceptual experience. Neurocase. 2013; $19(5): 445-450$. 


\section{Neurology}

Clinical Reasoning: An 81-Year-Old Woman Who Insisted the Hospital Was Her Home

Tara C. Carlisle, Michael P.H. Stanley, Aneesh B. Singhal, et al.

Neurology 2021;97;e1632-e1636 Published Online before print June 18, 2021

DOI 10.1212/WNL.0000000000012392

This information is current as of June 18, 2021

\section{Updated Information \&} Services

References

Subspecialty Collections

Permissions \& Licensing

Reprints including high resolution figures, can be found at: http://n.neurology.org/content/97/16/e1632.full

This article cites 9 articles, 2 of which you can access for free at: http://n.neurology.org/content/97/16/e1632.full\#ref-list-1

This article, along with others on similar topics, appears in the following collection(s):

Aphasia

http://n.neurology.org/cgi/collection/aphasia

Assessment of cognitive disorders/dementia

http://n.neurology.org/cgi/collection/assessment_of_cognitive_disorder S_dementia

Cardiac

http://n.neurology.org/cgi/collection/cardiac

Information about reproducing this article in parts (figures,tables) or in its entirety can be found online at:

http://www.neurology.org/about/about_the_journal\#permissions

Information about ordering reprints can be found online:

http://n.neurology.org/subscribers/advertise

Neurology ${ }^{\circledR}$ is the official journal of the American Academy of Neurology. Published continuously since 1951, it is now a weekly with 48 issues per year. Copyright () 2021 American Academy of Neurology. All rights reserved. Print ISSN: 0028-3878. Online ISSN: 1526-632X.

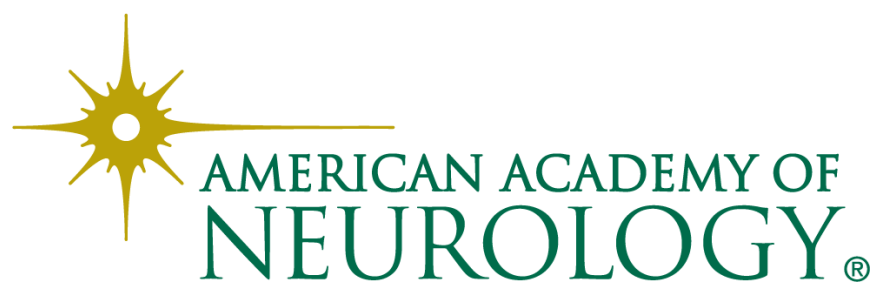

